\title{
XXIII. On electric currents through air films
}

\section{Prof. A. Anderson}

To cite this article: Prof. A. Anderson (1913) XXIII. On electric currents through air films , Philosophical Magazine Series 6, 26:152, 351-353, DOI: 10.1080/14786441308634978

To link to this article: http://dx.doi.org/10.1080/14786441308634978

$$
\text { 册 Published online: } 08 \text { Apr } 2009 .
$$

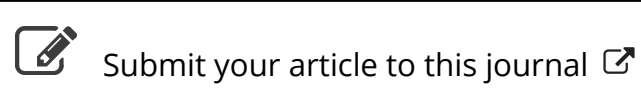

\footnotetext{
Џll Article views: 3
}

Q View related articles $\square$

7 Citing articles: 1 View citing articles 5 


\section{On Electris Currents through Air Films. By Prof. A. Anderson *.}

T $\mathrm{N}$ the Philosophical Magazine for May 1912 there is a 1 short paper in which some experiments on electric currents in air at atmospheric pressure are referred to. Mr. H. N. Morrison, who is now working at the subject, has obtained further results, some of which, I venture to think, are of sufficient importance to be communicated before all of them can be presented in their final form.

Fig. 1.

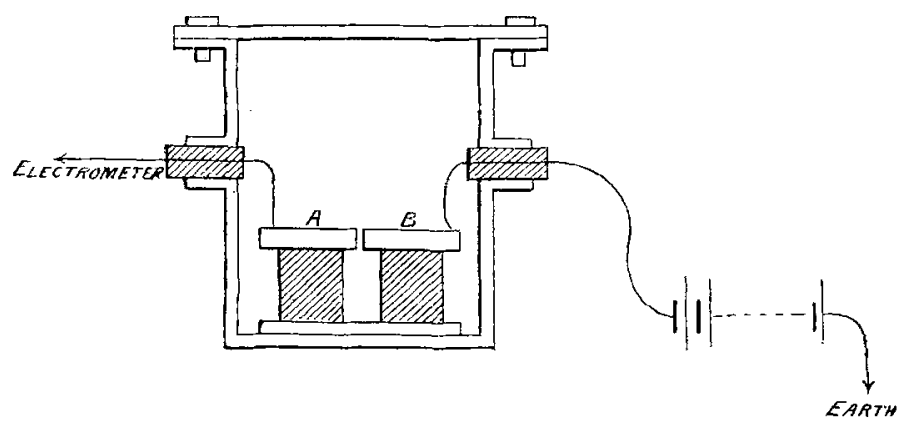

Two brass bars, A and B, fig. 1, with carefully worked plane ends each of area $1.15 \mathrm{sq} . \mathrm{cm}$., are mounted firmly on paraffin blocks stuck on a copper plate, so as to include between them a rectangular film of air of a uniform thickness of about $.002 \mathrm{~cm}$. This apparatus is placed inside an earthed copper box which can be made nearly air-tight. Air, after having been passed through drying-tubes and tubes containing closely packed glass-wool, was passed slowly at intervals through this box for several days, and no air was afterwards admitted which had not been similarly treated. If $B$ be connected to one of the poles of a battery of cells and A to one of the terminals of a quadrant electrometer, the electrometer will charge up and the current can be measured easily. If $A$ and $B$ are different metals and $B$ earthed, the electrometer will also charge up, and at a surprisingly quick rate, the final deflexion giving the contact difference of potential. Indeed this is the easiest method of measuring contact differences, no special ionizing agent being necessary.

Currents between two brass bars as above described are

* Communicated by the Author. 
produced by very small potential differences and increase with the applied voltage, for pressures up to about 80 volts, approximately according to Ohm's law, after which the increase of current is much more rapid than the increase of voltage.

The questions arise-why does a current pass? and what carries it? To say that there is metallic contact produced by the electrostatic pressure between the plates will not solve the difficulty, at any rate in the case where the metals are different and no potential applied. When the metals are the same and a potential applied, experiment shows that the current diminishes when the pressure of the air is diminished, and, if the pressure is not made too small, and the air in the copper box not kept at the low pressure too long, again increases as the pressure is increased, the current, however, for the same pressure being somewhat smaller when the pressure is being increased than when it is being decreased. This is shown in fig. 2 for an applied difference of potential

Fig. 2.

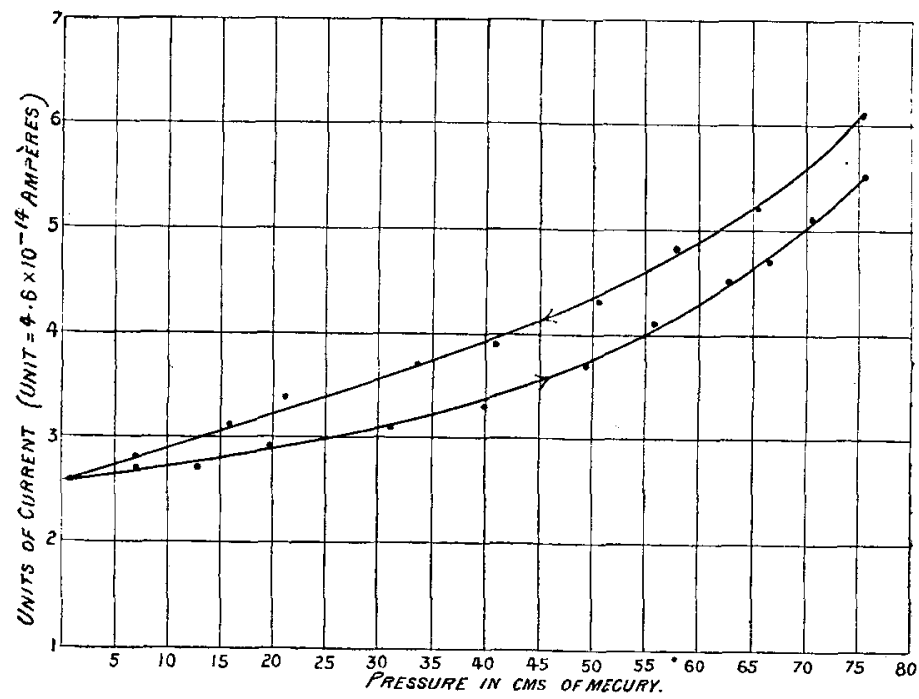

of 100 volts. Here the pressure was diminished to that equivalent to 8 millimetres of mercury.

This dependence of the current on the pressure of the air 
seems inconsistent with an explanation based on the assumption of metallic contact.

Another possible explanation would be the presence of dust or ions in the air contained in the copper box. Every effort was made to free the air from dust, but, no doubt, some still remained. That the current is not due to dust seems to be proved by the following experiment. When the applied potential was 100 volts, the pressure was reduced to about 2 millimetres of mercury and kept at that for about 20 minutes, with the result that the current stopped completely, or was so small as not appreciably to affect the electrometer. The pressure was then increased very gradually by allowing air to go slowly through the drying apparatus and the glass-wool; and it was not until the pressure became nearly half an atmosphere that an appreciable current was observed. It then increased rapidly with increase of pressure, and finally, at atmospheric pressure, became nearly what it was before the box was exhausted. In all cases $A$ and $B$ were kept earthed unless when a measurement of current was being made, the measurement lasting for about half a minute.

If the conductivity were due to dust, there does not seem to be any reason why there should be such an enormous lag between the increase of pressure and the increase of potential.

If the conductivity were due to the presence of ions throughout the air in the copper box, it ought to be possible to diminish it by applying a high voltage to one of the bars so as to remove them. But if this is done the current afterwards becomes much greater, provided the high voltage is not applied too long.

Everything, therefore, points to the formation of ions in the surfaces of the film of air in contact with the ends of the bars, which become available as carriers when the opposing surfaces are close enough. These ions can be removed by removing the air; and when the air is introduced again they are again formed, but not instantaneously. Their formation requires time. It is probable that such layers of ions exist at the surfaces of all hodies in contact with the atmosphere, and that they play a prominent part in coherer action and in all cases of the discharge of bodies by contact. 